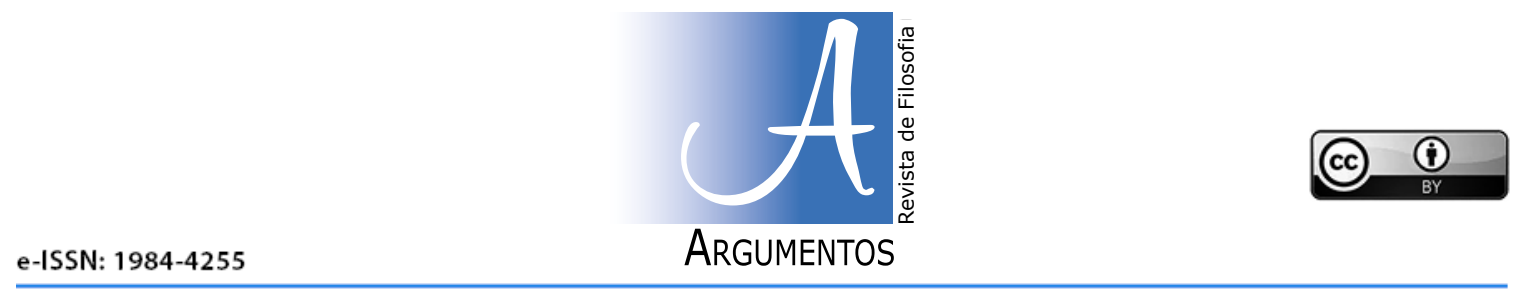

D0I: $10.36517 /$ Argumentos.26.4

\title{
Elenchos e educação moral no Sofista de Platão
}

\section{Elenchus and moral education on Plato's Sophist}

\author{
José Wilson da Silva \\ https://orcid.org/0000-0001-9109-6527 - E-mail: zewilson.silva@uece.br
}

\begin{abstract}
RESUMO
Uma das características marcantes de Sócrates é o seu modo de examinar. Através da investigação apoiada em uma série de perguntas intercaladas por respostas de um interlocutor, Sócrates segue um caminho de negação das teses que lhes são apresentadas até chegar a um total impasse nesta busca. Sócrates chama de elenchos (refutação) ao seu procedimento habitual e ficou bem conhecido pelo o que nos é apresentado nos primeiros diálogos de Platão. Por outro lado, há no diálogo Sofista, na sexta definição, a associação do elenchos à atividade sofística e, ainda, é apresentado como um método educacional. Estes dois casos são matéria de debate entre os estudiosos, que consideram que o elenchos nesta passagem do Sofista não é o mesmo método dos primeiros diálogos de Platão, principalmente, por ser considerado um método educacional; já o elenchos dos primeiros diálogos serviria apenas para mostrar que o interlocutor sustenta opiniões conflitantes sobre os assuntos morais. Pretendemos, portanto, mostrar que Platão não está apresentando uma nova compreensão do elenchos e, ainda, que já era pensado como um método educacional em diálogos anteriores.
\end{abstract}

Palavras-chave: Platão. Sofista. Refutação. Educação Moral. Ignorância.

\begin{abstract}
One of Socrates' striking features is his way of inquiring. Through investigation supported by a series of questions interspersed with the answers of an interlocutor, Socrates follows a path of negation of the theses presented to them until reaching a total impasse in this search. Socrates calls elenchos (refutation) his usual procedure and it was well known for what is presented to us
\end{abstract}


in Plato's first dialogues. On the other hand, in the Sophist dialogue, in the sixth definition, the association of elenchos with sophistic activity is also presented as an educational method. These two cases are a matter of debate among scholars, they consider that the elenchos in this passage of the Sophist is not the same method as Plato's first dialogues, mainly because it is considered an educational method; but the elenchos of the first dialogues would only serve to show that the interlocutor holds conflicting opinions on the moral issues We pretend, therefore, to show that Plato is not presenting a new understanding of the elenchos and yet that it was already thought of as an educational method in previous dialogues.

Keywords: Plato. Sophist. Refutation. Moral Education. Ignorance.

\section{Introdução}

O diálogo Sofista é conhecido principalmente por ter uma ampla e instigante investigação no âmbito ontológico - aqui Platão aborda com maestria as grandes questões a respeito do ser e do não-ser (a bem conhecida digressão ontológica, 241c-251a). A grande maioria dos pesquisadores, quando se dispõe à exegese deste famoso diálogo, centra-se nas questões concernentes aos problemas ontológicos, graças a enorme reviravolta que Platão opera ao determinar que o não-ser é (Sof. 237a). A acuidade do pensamento platônico, por outro lado, não se limita apenas a uma revisão interna da sua própria filosofia, o resultado da sua empresa se estende inclusive às estruturas ontológicas hegemônicas que eram vigentes até o momento da escrita desta referida obra. Assim os chamados amigos da terra e os amigos das Formas (Sof. 245e-249d), os proponentes da tradição metafísica anterior, não foram poupados do crivo do exame platônico, o filósofo expõe os problemas cabais que comprometem cada uma destas correntes de pensamento.

Evidentemente, não se muda as bases de um sistema filosófico, no que concerne ao pensamento antigo, sem interferir em toda a sua estrutura, pois as compreensões acerca das outras disciplinas filosóficas devem se alinhar às novas bases; em especial a epistemologia, pois não é possível uma teoria do conhecimento que esteja desvencilhada de uma ontologia, como é bem claro na filosofia platônica. A reformulação da teoria do conhecimento é matéria acordada entre muitos especialistas que reconhecem que uma das marcas da terceira fase ${ }^{1}$ da produção intelectual platônica é a apresentação da novidade da ciência dialética.

A dialética platônica, no momento da sua última fase, passa a ser identificada com um método chamado diairesis (divisão), que visa alcançar uma definição por meio da divisão de um gênero em suas espécies e assim sucessivamente até chegar ao objetivo desejado. Desta forma, Platão teria, paulatinamente ao longo da sua carreira intelectual, abandonado os métodos que eram os principais nas duas primeiras fases, o método elênctico/refutativo e o método hipotético (dado o desenvolvimento da hipótese das Formas Inteligíveis) respectivamente, e adotado o método da divisão. Curiosamente, no diálogo aqui abordado, o Estrangeiro de Eleia, a principal personagem do diálogo, discorre, em um pequeno trecho do diálogo, sobre a aplicabilidade de um certo método no processo educativo (pois compreende que é parte da educação a liberação dos indivíduos das amarras da ignorância ao eliminar suas opiniões falsas).

\footnotetext{
1 Sem entrarmos nas discussões relativas à cronologia das obras platônicas, estamos aqui considerando que o diálogo Sofista é da terceira fase. Para uma discussão sobre a cronologia dos diálogos, ver Branwood (1992). Para as discussões relativas às fases da produção intelectual platônica, ver as referências em Kahn (1996, pp. 38-39) acerca dos proponentes das interpretações unitária e desenvolvimentista.
} 
Valendo-se disto, neste trecho do diálogo, o método que cumpre a função de eliminar as opiniões falsas, ou melhor, de extirpar a ignorância do pensamento de um interlocutor ou discípulo é o elênctico ${ }^{2}$.

A passagem revela que Platão, em vez de considerar o método dialético como o candidato acertado para o papel didático na formação moral e intelectual dos indivíduos, ele considera que este papel é atribuído ao método elênctico. Coerentemente, para estarmos em concordância com este diálogo e seu lugar na cronologia da produção platônica, não podemos perder de vista que somente é reservado ao filósofo o método dialético, ou seja, há somente um tipo de método adequado para o exame das realidades inteligíveis e aquele que aplica esta atividade nas suas buscas são os filósofos; o que não impede que este mesmo filósofo detenha a habilidade e o conhecimento dos outros métodos. Portanto, o método elênctico, por não ser exclusivo dos filósofos, pode ser empregado por outros especialistas, mormente os sofistas.

A função do método elênctico, neste momento da sexta definição do sofista, é vista por Platão como uma atividade purgativa - um certo tipo de mal é eliminado da alma humana e, ao ter este mal eliminado, ela se torna purificada. Este certo tipo de mal na alma é a ignorância, que Platão diz ser a opinião falsa, e cabe ao método elênctico a função purgativa de eliminá-la. A aplicabilidade de um método que suprime as opiniões falsas e que leva luz à visão obnubilada dos ignorantes, abrindo caminho para a verdade e elevando o ser humano à sua condição de excelência é acertadamente chamada de educação, por isso mesmo que na visão platônica o método elênctico é uma atividade educacional.

Lembremos que o especialista que detém a capacidade de exercer essa função é o sofista de acordo com a sexta definição, mas que o Estrangeiro tem o cuidado de afirmar que se

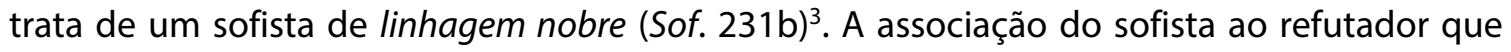
cumpre a função educativa de eliminar a ignorância da alma de seus interlocutores causa espanto se pensarmos na exposição negativa feita por Platão tanto nas cinco definições anteriores quanto ao que ele declara ao longo do seu corpus.

A passagem é inusitada também por outro aspecto. Se tivermos em conta que este método refutativo sempre foi associado a Sócrates, e se for verdade que Platão se esforçou para desvencilhar a associação de seu mestre aos sofistas, esta passagem do Sofista dá a entender que os limites entre o sofista e o próprio filósofo estão borrados; como é deixado bem claro pela imagem do lobo e do cachorro como seres semelhantes mas opostos (Sof. 231a). Portanto, na atividade que diz respeito à educação dos indivíduos, mormente os mais jovens, os filósofos possuem um concorrente que cumpre a mesma função de purificador das almas.

O método elênctico, até então, aplica-se à esfera intelectual, dado que é um purgativo da ignorância, porém, o elenchos sempre foi reconhecido como um método relativo à esfera moral. Tradicionalmente, os comentadores consideram não existir limites consideráveis entre esfera prática e teórica na filosofia platônica - mas aqui parece que essa separação está presente, já que a discussão na sexta definição parece realmente operar uma diferenciação entre essas esferas, pois, se atentarmos para a distinção entre os males da alma e suas respectivas técnicas de purificação, podemos chegar à conclusão que Platão considere como separadas. Os males da alma são a doença e a fealdade, os exemplos de doença são a injustiça, intemperança e covardia, ou seja, são vícios; e os exemplos de fealdade são os diversos tipos de ignorância. Apesar desta distinção, aparente ou não, defendemos que o elenchos contempla ambas

\footnotetext{
2 Zaks (2018) argumenta que o elenchos está aplicado em todo o argumento do diálogo, como é o caso dos exames das explicações do ser pelos predecessores.

3 Para uma discussão sobre essa expressão ver Trevaskis (1955) e Notomi (1999, 64-68).
} 
as esferas, o que vai de encontro à visão quase unânime dos especialistas que o enxergam como uma cura purgativa com fins morais ${ }^{4}$. Logo, o elenchos tem aplicabilidade não apenas nas questões de ordem moral, ele se assenta também nas questões de ordem intelectual. Dada isto, o elenchos não seria apenas um método para a aprendizagem de conteúdos intelectuais, é também um método útil na formação de indivíduos virtuosos.

\section{O elenchos como método educacional}

A discussão sobre o método elênctico entremeia a argumentação sobre o ensino e educação. Pelo método da divisão, usado nesta parte inicial do diálogo (Sof. 226b-231c), a diakritiké (arte de discriminar, separar) é tomada como um gênero de técnica a ser dividido em suas espécies, a saber: a arte que separa o melhor do pior (kathartikế: técnica da purificação) e a arte que separa o semelhante do semelhante - para esta última Platão não possui um nome. Na última ramificação destas secções, o método elênctico é um método catártico que purifica a alma daqueles que foram submetidos a este tipo de exame.

$\mathrm{Na}$ arte de separar o melhor do pior, a arte da purificação, temos duas divisões: uma relativa ao corpo e outra relativa à alma. A catarse tem por finalidade separar ou apartar, seja no corpo seja na alma, aquilo que for o pior, dito de outra maneira, expurgar o mal. Platão, ao se referir a este mal, usa o termo ponéría para representar o mal tomado de uma perspectiva geral, pois ele ainda irá dividir a maldade em mais dois tipos. Nesta divisão da maldade, Platão também classifica suas subdivisões em dois tipos de males de maneira geral: eles são uma doença e uma fealdade. O que é uma doença no corpo não é o mesmo daquela da alma, mas de maneira geral tanto uma como a outra são formas de sedições, ou melhor, um corpo ou uma alma está doente quando existe neles uma desunião entre coisas que são, por natureza, aliadas (Sof. 228a). A fealdade, de modo geral, é uma desarmonia (seja a fealdade no corpo seja a fealdade na alma).

As ramificações relativas à purificação dos males do corpo serão deixadas de lado, já que o exame pretende apreender o que é o sofista, cuja atividade não é relativa ao cuidado do corpo, mas sim ao da alma. Logo, o interesse está voltado para a purificação dos males da alma. Contudo, a doença da alma, que é uma sedição ${ }^{5}$ interna, é exemplificada no texto por um conflito entre opiniões e apetites, entre o ardor e os prazeres, entre a razão e as dores (Sof. 228b). Platão enumera três tipos de sedições: primeiramente, ele lista dois tipos: a intemperança (akolasía) e a injustiça (adikía), em 228e; e, posteriormente, acrescenta a covardia (deilía), em 229a. Os exemplos de sedições lembram demasiado a argumentação da partição da alma na República, os vícios e todas as injustiças que são explicados pelos conflitos internos à alma ${ }^{6}$ - o termo sedição também é empregado na República na sua aplicação para todo conflito interno ${ }^{7}$. Por conseguinte, segundo a argumentação da República, a intemperança (akolasía) é exatamente um conflito na alma entre o elemento que comanda e o elemento comandado; há injustiça (adikía) na alma quando um elemento cuja natureza não é afeita ao governo cumpre a função de governante, ou seja, há sedição porque um elemento interfere na função do outro elemento; a covardia (deilía) é não "dar ouvidos" aos preceitos do elemento racional relativos ao que deve ser ou não ser temido, mostrando aqui também que o elemento racional e o ele-

\footnotetext{
4 Sobre o debate em torno da educação moral socrática, ver Gendron (1999).

5 Stasis (бтáoıç, Sof. 228a).

6 Dorter (1990) já havia percebido a presença do argumento da tripartição da alma no Sofista.

7 Por exemplo, República, Livro IV, 442d.
} 
mento irascível não estão atuando em uníssono. As narrativas na República e no Sofista parecem ser bastante similares e acreditamos que a teoria da alma tripartite em Platão está presente até seus últimos diálogos desde o momento de seu aparecimento.

No que concerne ao mal que é a fealdade, a assimetria (ametrías) é o que a define, isto é, toda e qualquer fealdade é uma assimetria. Ao tratar sobre a assimetria, Platão assenta que a ela é algo que participa do movimento. Para entendermos o que ele quer significar com isto, devemos ter em mente que a compreensão de movimento para o pensamento grego antigo não se limita ao que nosso pensamento moderno concebe, ele é bem mais amplo. A compreensão mais conhecida é que o movimento para o pensamento antigo tanto é deslocamento espacial quanto mudanças qualitativas. Platão não expressa se o caso aqui é deslocamento ou mudança qualitativa, mas se preocupa com a apresentação de uma definição geral de movimento (é tudo o que pretende atingir um fim, Sof. 228c). A fealdade na alma é um erro cognitivo em que o indivíduo acredita ter atingido a verdade, mas erra o alvo, ou melhor, é um movimento em direção à verdade que se desvia de seu objetivo. Esse erro cognitivo é, portanto, a ignorância (ágnoia, Sof. 228d).

Com base nisto que foi aqui apresentado sobre a argumentação presente na sexta definição do sofista neste referido diálogo, Platão determina que, para toda sedição na alma, a técnica a ser utilizada é a justiça corretiva (kolastiké, Sof. 229a); para todas as formas de ignorância (sýmpasa ágnoia), a técnica apropriada é o ensino (didaskaliké, Sof. 229a).

O ensino também se divide em duas partes, pois há também duas formas de ignorância. O que implica, portanto, na existência de duas artes do ensino para cada tipo de ignorância na alma. Platão apenas trata de um tipo de ignorância, que ele diz ser a maior e a pior forma, definindo-a como a crença em acreditar que se sabe um certo assunto quando, em realidade, não se sabe exatamente nada sobre ele. O nome dado por Platão para este tipo de ignorância é amathia e a técnica purgativa que lhe é correspondente é a paideia.

Platão não nomeia a outra espécie de ignorância, ele apenas revela que a técnica purgativa que lhe corresponde é a instrução técnica (dēmiourgikế). Da mesma forma, não há grandes detalhes sobre esta última, mas podemos inferir que não é uma técnica que faz uso do discurso para o ensino, pois essa atividade é reservada à paideia. Quando Platão parte para a divisão da paideia em suas espécies, ele fala "parece-me que, no ensino pelo discurso [тñৎ દ́v

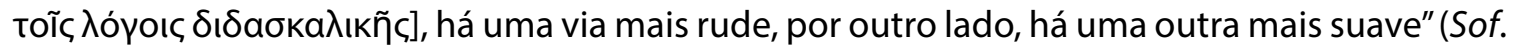
229e). Ao declarar que esta técnica é feita pelo discurso, dá a entender que a outra é feita por outros recursos.

As duas partes do ensino por meio do discurso ou paideia são a admoestação (nouthetētikế) e a refutação (élenkhos), a divisão chega ao seu termo e o sofista é definido como refutador. O elenchos é explicado em 230b-c como uma mostração das contradições

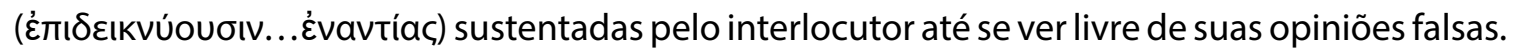
Com efeito, o elenchos é um método puramente negativo, ele ocorre pelo arrasamento, provocado por um questionador, do que foi sustentado pelo interlocutor. O processo de refutação, para ocorrer, necessita primeiramente que o interlocutor assuma uma tese $P$, que é a matéria que o questionador necessita para produzir a refutação, em seguida, o questionador apresenta uma tese $Q$, que é a negação da tese $P$, com o objetivo de consentimento do interlocutor. Se o interlocutor aceitar a tese $Q$, o questionador mostra que ele alberga opiniões contrárias, e este entrechoque entre as opiniões é o suficiente para produzir a refutação. A consequência do elenchos é o abandono de uma das opiniões; em realidade, a opinião falsa é abandonada quando confrontada com a verdade, e desperta o sentimento de vergonha, que é um grande reforço para a clivagem intelectual e/ou moral, ou seja, para o processo educacional. 


\section{O elenchos no Sofista e o elenchos nos diálogos socráticos}

O que os especialistas costumam chamar de método elênctico socrático é um certo tipo de procedimento investigativo apresentado nos primeiros diálogos platônicos. Não há nestes diálogos uma preocupação, por parte de Platão, em produzir uma exposição concernente aos aspectos formais deste método. Por outro lado, o que nos permite tratá-lo enquanto um método é o padrão existente nesse procedimento que Sócrates aparece aplicando nesses primeiros escritos. Porém, a sexta definição do sofista apresenta o elenchos metodicamente e acrescenta elementos que não foram mostrados nos primeiros diálogos tais como o papel da vergonha no processo de clivagem mental, os efeitos calmantes da refutação e, o mais importante aqui, que a refutação é um método de ensino.

O fato de que a refutação é vista como um método de ensino aqui na terceira fase platônica é a comprovação para alguns estudiosos de que o refutador neste caso não pode ser identificado com Sócrates, já que ele costuma expressar que não é um mestre e, portanto, não ensina nada. Realmente existem passagens na obra platônica em que Sócrates deixa isto claro, assim como existem outras passagens em que ele assume ensinar algo. As passagens nas quais Sócrates diz ensinar são as seguintes: Apologia 21b e 35c, Láques 195a e Górgias 457c-d (assumimos que os diálogos aqui listados são obras da primeira fase). Logo, considerar que o elenchos aqui no Sofista não pode ser atribuído a Sócrates porque é um método educativo, e Sócrates já havia declarado não ensinar nada, não é uma interpretação segura e definitiva já que há outras passagens nas quais Sócrates afirma ensinar.

É intrigante estas duas figuras de Sócrates (o que afirma ensinar e o que nega ensinar), delas é possível supor que Platão as representa de acordo com suas pretensões consoantes com a exposição de cada diálogo, como muitos especialistas solucionaram esse problema - nas obras iniciais, a argumentação presente nestes diálogos não põe a necessidade de um Sócrates educador, apenas nas obras posteriores ele é representado como educador por causa de teorias como a da imortalidade da alma. Há a interpretação de Zacks que busca compreender estas distintas narrativas assumindo a seguinte hipótese: "ele nega ser um professor em um sentido, mas está pronto para se identificar como um professor em um outro sentido" ${ }^{8}$. Este comentador observa que o sentido no qual Sócrates nega ensinar diz respeito aos dois tipos de ensino tratados na sexta definição do sofista, a saber: a instrução técnica (229d) e a admoestação (229e-230a). Já o sentido que corresponde à afirmação socrática de que ele próprio é um professor é o ensino pelo método refutativo.

Esta forma de interpretar é completamente especulativa, já que não existe comprovação textual para corroborar a hipótese de Zacks. Nós, por outro lado, temos em mente uma outra hipótese, mantendo a mesma ideia de que são sentidos distintos para a educação, porém, reconhecemos que os sentidos são outros, a saber: uma concepção de educação compreendida como transmissão de conteúdos e uma concepção de educação em que o conhecimento é "auto-concebido". Assim, quando Sócrates nega ser um professor é no sentido de ser um educador que transmite algum conteúdo para seus discípulos, mas quando afirma ensinar é no sentido de fazer o discípulo auto-conceber o conhecimento.

Nossa hipótese se baseia em duas passagens do corpus platonicum, a primeira é a declaração socrática que nega a concepção de educação enquanto transmissão, que se encontra no

\footnotetext{
8 Zacks (2018), p. 377, n. 19.
} 
Banquete, e a segunda é correspondente à educação como conhecimento auto-concebido, que se encontra no diálogo Mênon.

A menção ao experimento dos vasos comunicantes apresentada no início do Banquete comprova que Sócrates não concebe que o conhecimento seja um conteúdo que possa simplesmente ser transmitido para um indivíduo ignorante. A passagem é a seguinte: "Seria de uma prosperidade, Agatão, se a sabedoria fluísse daquele mais pleno [de conhecimento] para o mais vazio [de conhecimento], quando tocássemos uns aos outros, como a água de um copo que flui, por meio do fio de lã, do [recipiente] mais pleno para o [recipiente] mais vazio". Sócrates demonstra aqui uma postura cética a essa possibilidade de transmissão de conhecimento.

Parte da crítica a essa forma de compreender a educação, como transmissão do conhecimento, encontra eco na passagem 81d-e do diálogo Mênon quando Sócrates menciona os seus efeitos nocivos aos que são por ela educados. O ponto central discutido nessa passagem é a apresentação da tese da reminiscência, que é tida como o próprio processo de todo aprendizado feito com auxílio de um mestre que conduz o discípulo a encontrar por si mesmo o conhecimento. Desta forma, os indivíduos que são educados pela ideia de transmissão de conhecimento tornam-se, segundo Sócrates, preguiçosos ou inativos e débeis - os que são educados desta maneira não são agentes ativos na aquisição do conhecimento. O que não é o mesmo para os que são educados na outra maneira, cujo processo de aprendizado é pela rememoração, esses são diligentes e inquiridores, pois são ativos na busca do conhecimento. No momento em que Sócrates demonstra essa forma de educação em que o aprendizado é rememoração, que é a famosa passagem da solução do problema matemático pela criança escrava da casa de Mênon, ele o faz pelo seu costumeiro método refutativo. Sócrates conduz o raciocínio para a solução do problema refutando as respostas dadas pela criança até fazê-la cair em aporia.

O problema matemático trata sobre a incógnita relativa ao lado do quadrado cuja área é de $8 \mathrm{~cm}^{2}$. Para solucionar esta dificuldade, Sócrates toma por base o quadrado de lado $2 \mathrm{~cm}$ e faz com que a criança pense que um quadrado cujo lado seja o dobro deste tenha também a área que seja o dobro. Essa ideia é refutada, pois o quadrado que tenha o lado que seja o dobro do primeiro quadrado tem área de $16 \mathrm{~cm}^{2}$, o que ultrapassa em duas vezes a primeira área. A criança então pensa que deva ser o quadrado cujo lado esteja entre $2 \mathrm{~cm}$ e $4 \mathrm{~cm}$, que é o lado $3 \mathrm{~cm}$, mas uma vez mais, sua ideia é refutada porque a área deste último quadrado ainda não é a área de $8 \mathrm{~cm}^{2}$, pois a ultrapassa em $1 \mathrm{~cm}^{2}$. A criança, com isto, é levada a cair em aporia. Aqui temos a aplicação padrão do método refutativo socrático e, durante o raciocínio, Sócrates faz a seguinte declaração: "vês, Mênon, como não ensino nada disso, mas estou perguntando tudo? Neste momento, ele acha que sabe (...)" (Men., 82e - itálicos nossos). Em um primeiro momento, a criança acha que sabe qual é o lado buscado, mas, na realidade, ela não sabe, ou seja, ela é ignorante sobre este assunto, ele tem uma opinião falsa, ou melhor, uma amathía. Assim, temos aqui o método refutativo sendo usado no processo educativo que elimina a amathía.

Está bem claro, pelo menos nestes dois diálogos aqui tratados, que Sócrates concebe duas concepções de educação, ambas opostas e inconciliáveis e apenas uma delas ele admite praticar. Sócrates também concebe que apenas uma destas formas de educação realmente nos livra de nossa ignorância, a rememoração. A passagem relativa à rememoração no Mênon possui a aplicabilidade do método refutativo no processo de ensino, Sócrates aqui retira as opiniões falsas (a crianças acha que sabe a solução para o problema), que são obstáculos para a aquisição do conhecimento. Esta descrição apresenta elementos que são os mesmos presentes na passagem relativa à sexta definição: método refutativo, ensino e a amathía. Logo, o elenchos no Sofista pode perfeitamente ser atribuído ao Sócrates sem criar nenhum problema de interpretação. 


\title{
Por que o elenchos é o mais apropriado para eliminar a amathía?
}

Educação deve ser compreendida como processo de eliminação da ignorância, que possibilita a aquisição do conhecimento. Como existem múltiplas espécies de ignorância, os processos educativos serão correspondentes a cada uma destas espécies. O elenchos, como sabemos, é um método empregado para a eliminação de uma espécie de ignorância chamada amathía (opiniões falsas tomadas como verdadeiras), o que significa que aquele que as suporta não percebe a falsidade delas. Considerar que coragem resulta do medo da morte ${ }^{9}$, que a morte é um mal ${ }^{10}$, que é justo fazer o mal para quem comete injustiças ${ }^{11}$, que os deuses fazem o mal ${ }^{12}$, que o prazer é o bem ${ }^{13}$, que desejar o que nos é idêntico é amor ${ }^{14}$, que se privar de prazeres em nome de outros é temperança ${ }^{15}$ são exemplos de opiniões falsas - pelo menos uma destas opiniões se encontra em quase todos os indivíduos, pois elas aparentam ser verdadeiras e por isto mesmo induzem ao erro quem as mantêm.

Enquanto os indivíduos tomarem tais opiniões como verdadeiras, sempre viverão uma vida no erro porque as aparências podem ser enganosas. Também estarão inclinados a permanecer no erro mesmo que lhe seja apresentado um conhecimento contrário. Apenas apresentar proposições, discursos ou raciocínios que se opõem uns aos outros não é suficiente para operar uma clivagem intelectual e moral, ou seja, não basta mostrar para estes indivíduos enganados o outro lado da moeda. Para estes casos, a aquisição do conhecimento verdadeiro deve ter que necessariamente passar pela negação do conhecimento falso existente. Portanto, deve-se primeiro eliminar a falsidade para poder dar espaço para o conhecimento e para a verdade. Platão deixa isto bem claro na seguinte passagem:

\begin{abstract}
Pois, minha querida criança, os purificadores [da alma], como os médicos em relação aos corpos, que têm por costume não poder beneficiar o corpo antes de ter recomendado o alimento até que os obstáculos internos não tenham ainda sido retirados, o mesmo também pensaram para a alma, ela não terá a vantagem dos conhecimentos recomendados até que, pela refutação, a pessoa refutada é levada a um estado de vergonha, livrando-se das opiniões que impediam o conhecimento" (Sof. 230b-d).
\end{abstract}

O tipo de ignorância (amathía) que encerra o método refutativo é a opinião falsa, o engano de não saber, mas achar que sabe. Mas o que confere a qualidade de ser falsa à opinião? A resposta de Platão é a participação no não-ser. Após a digressão ontológica em que foi demonstrado que o Ser se entrelaça com o não-Ser, Platão explica que um certo grupo X de gêneros se entrelaçam com um outro grupo $Y$ de gêneros, mas que não se entrelaça com outros grupos W, Z, P e assim por diante. Além disso, os chamados gêneros supremos, como o Ser e o não-Ser, se entrelaçam como todos os outros. Em especial, o entrelaçamento dos gêneros com o não-Ser é a condição que possibilita a falsidade (Sof. 260b-e), porém, o não-Ser deve ser concebido como alteridade (tudo o que não for o gênero X). Logo, o falso é a combinação de um gênero com o que ele não é, por exemplo, afirmar que a diagonal do quadrado é comensurável

\footnotetext{
9 Fédon, 68d.

${ }^{10} \mathrm{Apologia}$, 29a-b: “Porque naturalmente, varões, temer a morte não é outra coisa senão parecer que se é sábio, quando não se é pois é parecer que se sabe o que não se sabe..., mas a morte, ninguém sabe se acaso não é o maior de todos os bens para o homem - porém a temem como se soubessem ser o maior dos males! E o que é isso, senão aquela ignorância [amathía] mais reprovável: a de se pensar saber o que não se sabe?".

${ }^{11}$ República, 332d.

${ }^{12}$ República, 380b-c.

${ }_{13}$ Protágoras, 351b-c.

${ }^{14}$ Banquete, 205e.

${ }^{15}$ Fédon, 68e-69a.
} 
é falso, pois é combinado ao gênero da diagonal algo que ela não é, pois, em realidade, a diagonal do quadrado é incomensurável.

Mas como saber que uma opinião é falsa? Primeiramente, é necessário compreender que o Ser para Platão é uma potência de comunicação e que a existência de todas as coisas é devido a esta potência. O Ser é, individualmente ou em sua totalidade, uma multiplicidade de relações das outras Formas entre si ou dele mesmo com todas as outras - na sequência do argumento, Platão reconhece o mesmo para o não-Ser enquanto alteridade. Em seguida, é necessário saber que estas múltiplas relações entre as Formas é a condição para o discurso, porque o próprio discurso indica este entrelaçamento (Sof. 259e). Os elementos mínimos que se entrelaçam para formar um discurso são o nome e o "verbo", que nos permite dar alguma indicação relativa "sobre as coisas que são, ou se tornaram, ou foram, ou serão; não apenas para nomear,

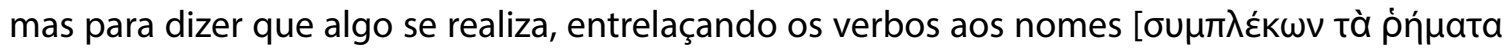

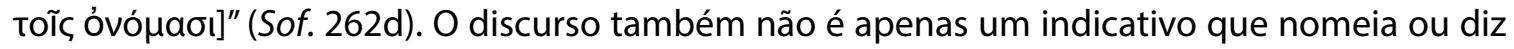

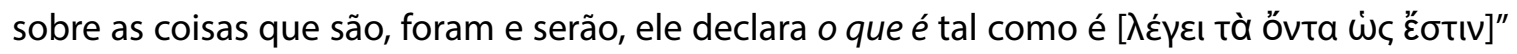
(Sof. 263b), ou seja, o verbo diz do nome algo que ele é - isto confere a qualidade de ser verdadeiro ao discurso, uma combinação homogênea entre nome e verbo; e ele também diz outras

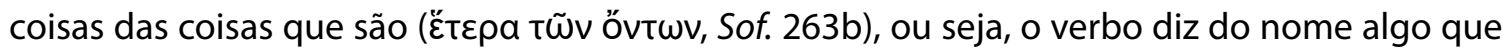
ele não é - isto confere a qualidade de ser falso ao discurso, uma combinação heterogênea entre nome e verbo. Logo, a qualidade de verdade ou falsidade do discurso diz respeito a um entrelaçamento de verbos e nomes que seja homogêneo ou heterogêneo respectivamente. Se tomarmos como exemplo o seguinte enunciado "Sócrates é branco", os termos que compõem este discurso simples, com base na ontologia descrita por Platão no Sofista, se combinam formando um todo sintético ou homogêneo. Por sua vez, no enunciado "Sócrates é aquático", os termos não se combinam, formando um todo heterogêneo. O enunciado "Sócrates é aquático" é falso, já que diz algo que não é de Sócrates.

Com base nisto, Platão assume que toda opinião, assim como as outras capacidades cognitivas (pensamento e juízo perceptivo) ${ }^{16}$, são derivadas do discurso ${ }^{17}$ (Sof. 263e-264a) desta maneira, o discurso interno, que ocorre na alma em pensamento, quando afirma ou nega é uma opinião. A opinião, portanto, é um certo tipo de discurso e, consequentemente, a sua verdade e falsidade se dá em razão do entrelaçamento, homogêneo ou heterogêneo, de verbos e nomes. Logo, a opinião falsa é uma combinação heterogênea, que afirma um atributo que não pertence à coisa (é justo fazer o mal ao inimigo) ou nega um atributo que pertence à ela (a justiça não é sabia nem capacita).

Esta é a base suficiente para entendermos a razão para o método refutativo ser o mais apropriado para eliminar a opinião falsa da alma, pois a opinião falsa, por ser exatamente uma expressão de uma contrariedade, já que combina atributos contrários às coisas, tende forçosamente a exibir suas incoerências quando confrontadas com as coisas tais como elas realmente são. O interlocutor ao perceber os seres tais como eles realmente são, constatam que certas opiniões que albergava na alma são insustentáveis, tornando impossível a permanência de ambas ao mesmo tempo.

Podemos elencar ainda um outro fator para compreendermos por que o método refutativo é o mais apropriado para cumprir a função educacional: a vergonha (lembremos que a refutação provoca o sentimento de vergonha naquele que sustentava opiniões falsas). Nem

\footnotetext{
${ }^{16}$ Diánoia e Phantasía.

${ }_{17}$ Notomi, p. 256: "We observe that the explanation of the three concepts, thought, judgement, and phantasia, is not a syntactical analysis (like the analysis of statement), but a relational analysis of these concepts in terms of statement".
} 
sempre a visão da verdade ou o conhecimento são suficientes para uma clivagem intelectual e/ ou moral, pois os pilares que sustentam certas opiniões são em sua maioria irracionais. Os raciocínios, apesar de serem necessários para o processo educacional, não são suficientes por não conseguirem atingir as camadas irracionais da alma, que possuem grande poder direcional das ações humanas. O sentimento de vergonha, que está ligado às noções de beleza e fealdade, quando está em conformidade com a atividade racional, serve como meio de controle e estabelecimento da ordem interna. Isto significa que as máximas racionais, que devem necessariamente ser proposições verdadeiras, serão os guias do pensamento deste indivíduo, ou seja, ocuparão o lugar das opiniões falsas, pois "a pessoa refutada é levada a um estado de vergonha, livrando-se das opiniões que impediam o conhecimento" (Sof. 230d). A refutação provoca o sentimento de vergonha porque revela um engano intelectual, significa que o enganado achava que tinha alcançado a verdade, mas errou o alvo. Relembremos que Platão explica que o movimento que mira a verdade, mas erra o objetivo, é uma assimetria. Assim, aquele que mantém opiniões falsas achando que são verdadeiras, contém em si uma assimetria. Evidentemente, a vergonha se opõe à toda fealdade, incluindo à fealdade na alma. Ocorre que a vergonha só nasce porque a fealdade, antes imperceptível, é revelada pela refutação. $\mathrm{O}$ indivíduo passa a perceber que era realmente ignorante quando identifica a contradição que mantinha. Por fim, estes são os motivos para o método refutativo ser o mais recomendado para o processo de passar da ignorância para a aquisição do conhecimento.

\section{Considerações finais}

A exposição da sexta definição do sofista é extraordinária - aqui Platão certamente demonstra a sua grande habilidade de conciliar perfeitamente o conteúdo filosófico com o modo de exposição. A sexta definição tem como conteúdo a apresentação do método refutativo como meio de eliminação do caráter difuso que atrapalha nossa capacidade de distinguir um conceito do outro, a verdade da falsidade, o que é do que não é, principalmente, quando estas coisas possuem semelhanças umas com as outras. Assim, o método refutativo passa a ser acomodado como uma técnica de purificação ao eliminar as obscuridades enganosas presentes em nossas almas. Neste momento do diálogo, Platão atribui a função de purificador de almas à atividade sofística, que sempre foi representada como a prática mais perniciosa na formação dos indivíduos. O caso é que a refutação não é exclusiva da sofística, Sócrates, por exemplo, é conhecido como um grande refutador. Eis aqui um motivo de controversa entre os comentadores, Sócrates e os sofistas são aproximados nesta definição - mesmo que a aproximação seja duvidosa. Da mesma forma, é posto em dúvida se o método como é representado aqui corresponde à refutação presente nos primeiros diálogos de Platão. A função do método como uma prática educativa parece não possuir nenhuma semelhança com o modo padrão de entender o método refutativo socrático e que por isso mesmo não pode ser atribuído a Sócrates.

A genialidade de Platão se apresenta quando as nossas interpretações se tornam conflitantes devido à combinação de gêneros que são contrários: o sofista como purificador e educador, que o assemelha ao modelo de filósofo para Platão (que é o próprio Sócrates). Da mesma forma, Platão tentou afastar de Sócrates a imagem de educador por causa da acusação de corruptor da juventude, mas na sexta definição do sofista, o seu método tão característico é um tipo de método educacional. Estas objeções e controvérsias, em realidade, tornam-se ainda mais interessantes porque a própria passagem também serve como seu próprio exemplo já que as combinações (sofista-educador, por exemplo) criam confusão. Talvez seja este o objetivo platônico, criar confusão para nos induzir à reflexão tal como faz o refutador, tal como faz 
Sócrates no Mênon. Como Platão já havia discutido na República 523a-d, há certas coisas que convidam à reflexão e outras não convidam, as que convidam são uma "mistura" de opostos. Estas misturas, ou combinações/entrelaçamentos, quando percebidas, forçam nosso intelecto a refletir, eleva-nos ao inteligível, aparta-nos do erro e nos coloca no caminho da verdade. É o que o método refutativo promove, a reflexão, mostrando as inconsistências que retiram as barreiras da ignorância, abrindo caminho para o conhecimento e a verdade.

\section{Referências}

BRANWOOD, L. Stylometry and Chronology. In The Cambridge Companion to Plato. Ed. Richard Kraut. Cambridge University Press, 1992.

DORTER, K. "Diaresis and the Tripartite Soul in the Sophist,.. Ancient Philosophy, v. 10, p. 41-61, 1990.

GENDRON, C. Reconsidering Socrates' Influence on Moral Education through the Elenchus. Philosophical Inquiry in Education, v. 12, n. 2, 1999.

KAHN, C. H. Plato and the Socratic Dialogue:The Philosophical Use of a Literary Form. Cambridge University Press, 1996.

LOTT, M. Ignorance, Shame and Love of Truth: diagnosing the sophist's error in Plato's Sophist. Phoenix, v. 66, n. 1/2, 2012, pp. 36-56.

NOTOMI, N. The Unity of Plato's Sophist: Between the Sophist and the Philosopher. New York: Cambridge University Press, 1999.

PLATON. Le Sophiste. Tradução de Nestor L. Cordero. Paris: GF Flammarion, 1993.

TREVASKIS, J. R. The Sophistry of Noble Lineage (Plato, “Sophistes 230a5-23269"). Phronesis, v. 1, n. 1, 1955, pp. 36-49.

ZAKS, N. Socratic Elenchus in the Sophist. Apeiron v. 51, n. 4, 2018, pp. 371-390.

\section{Sobre o autor}

\section{José Wilson da Silva}

Professor substituto da Universidade Estadual do Ceará e Professor Colaborador do Mestrado Acadêmico em Filosofia da Universidade Estadual do Ceará. Pós-doutorado, Doutorado e Mestrado em Filosofia pela Universidade de São Paulo, Graduado em Filosofia pela Universidade Estadual do Ceará e Doutorado Sanduíche na Université Libre de Bruxelles. Coordenador e Pesquisador do Grupo de Estudos em Filosofia Antiga da Universidade Estadual do Ceará (GEFA-UECE). Tem experiência em Filosofia Antiga (atuando principalmente nos seguintes temas: Metafísica, Epistemologia, Ética e Psicologia) e Ética (ênfase no tema da akrasía ao longo da história do pensamento filosófico). 